\title{
Design and Implementation of a Soil Matric Potential-based Automated Irrigation System for Drip Irrigating Fraser Fir
}

\author{
Pascal Nzokou ${ }^{1,3,5}$, Nicholas J. Gooch ${ }^{1,4}$, and Bert M. Cregg ${ }^{2}$
}

Additional index words. tensiometers, Abies fraseri, Christmas tree, data logger

SUMMARY. Irrigation of fraser fir (Abies fraseri) in Christmas tree production is gaining importance in the upper midwestern United States because of the intensive planting of this species out of its natural range. However, current scheduling practices rely on empirical observations with no monitoring of soil moisture and no use of automated irrigation system. The goal of this project was to design, construct, and implement a tensiometer-based automated irrigation system for fraser fir Christmas tree plantations that would (1) use existing technologies, (2) apply water based on changes in soil moisture content, (3) provide operational flexibility, and (4) interface with a computer for system changes, data collection, and system modifications. Soil tensiometers equipped with 4- to 20-milliampere transducers were installed at two drip-irrigated tree farms. Water on demand was controlled by soil moisture tension levels that triggered the stimulation of a relay wired to solenoids delivering irrigation water to the various treatments. The system functioned according to the design as expected. However, several issues associated with the need for regular maintenance of tensiometers, computer programming, and system wiring created some challenges regarding the reliability and transferability of similar system to commercial facilities.

$\mathrm{C}$ hristmas trees are short rotation perennial crops grown from seed in a nursery for 2 to 5 years, then moved into a plantation where they are raised for an additional 6 to 9 years until mature harvestable size of $\approx 6$ to $8 \mathrm{ft}$ (Nzokou et al., 2007). During the last decade, fraser fir has become the most economically important species grown for Christmas tree purposes in eastern United States (Koelling et al., 1992; Nzokou and Leefers, 2007). The species represents $\approx 40 \%$ of the estimated 3.5 million trees sold in Michigan, and it is also the main species in most producing states in the midwestern United States (Nzokou et al., 2007). However, fraser fir is native to the Appalachians Mountains of North Carolina and West

We gratefully acknowledge Korsons Tree Farm (Sidney, MI) and Gwinn Tree Farm (Horton, MI) for making fields available for this study and for donating labor, machines, and material used in this study. This study was partly funded by the Michigan State University Project GREEEN and the Michigan Christmas Tree Association.

${ }^{1}$ Department of Forestry, Michigan State University, 126 Natural Resources Building, East Lansing, MI 48824

${ }^{2}$ Associate Professor, Department of Horticulture and Department of Forestry, Michigan State University, A2 14 Plant and Soil Sciences Building, East Lansing, MI

${ }^{3}$ Assistant Professor

${ }^{4}$ Research Assistant

${ }^{5}$ Corresponding author. E-mail: Nzokoupa@msu.edu.
Virginia and considered as grown offsite when planted in other regions. As a consequence, in the upper midwestern United States, supplemental water must be applied to meet the physiological needs of this species (Koelling et al., 1992; Nzokou and Leefers, 2007). However, in current production practices, irrigation decisions are based on personal observations or empirical knowledge, with a rule of thumb guideline of 1 inch of water applied weekly in the absence of rainfall. This practice lags far behind modern irrigation practices in agriculture that use crop assessment, fixed time allocation, or soil moisture variation for scheduling irrigation.

Crop assessment methods include empirical crop water stress index used on various crops including corn [ $\mathrm{Zea}$ mays (Irmak et al., 2000; Yazar et al., 1999)], sunflower [Helianthus annums (Erdem et al., 2006)], watermelon [Citrullus lanatus (Orta et al., 2003)], tall fescue [Festuca arundinacea (AlFaraj et al., 2001)], and alfalfa [Medicago sativa (Payero et al., 2005)]. Daily changes in stem diameter (Fereres and Goldhamer, 2003) and visual indices (Jones, 2004) have also been used.

An alternative to crop assessment is to base irrigation scheduling on changes in soil moisture. Irrigation based on changes in soil moisture conditions is simple and easy to apply in practice (Jones, 2004). Soil-based assessments are made by regular monitoring of changes in soil moisture content using methods such as the "hand-feelmethod" (Klocke and Fischbach, 1984; VanderGulik, 2006) or using soil moisture measuring devices such as tensiometers and time domain reflectometers (TDRs).

Tensiometer-based systems have been used for high input agriculture, in which fertilizers and pesticides are applied (Young and Sisson, 2002). Using an automated irrigation system controlled by three different soil tension thresholds resulted in more efficient water use, reductions in pollution runoff, and increase in growth of 'Kardinal' rose (Rosa $\times$ bybrida) compared with a manually controlled systems (Oki et al., 1996). Other studies found that maintaining soil tension levels of $15 \mathrm{kPa}$ (Muñoz-Carpena et al., 2005) and $10 \mathrm{kPa}$ (Smajstrla and Locascio, 1996) resulted in the reduction of water use and no adverse effect was observed on the quality of tomato (Solanum lycopersicum) when compared with a manually irrigated system.

Automated systems can potentially decrease the overall cost of operating irrigation systems because of the reduction in water use (Cheek and Wilkes, 1994; Clark et al., 2007; Shukla et al., 2006). Furthermore, an automated water on demand system would be particularly useful for the production of short rotation intensively managed systems such as fraser fir Christmas tree production because large acreages are often irrigated taking several days or more to

\begin{tabular}{llll}
\hline $\begin{array}{l}\text { Units } \\
\text { To convert U.S. to SI, } \\
\text { multiply by }\end{array}$ & U.S. unit & SI unit & $\begin{array}{l}\text { To convert SI to U.S., } \\
\text { multiply by }\end{array}$ \\
\hline 0.4047 & acre(s) & ha & 2.4711 \\
1 & cbar & $\mathrm{kPa}$ & 1 \\
0.3048 & $\mathrm{ft}$ & $\mathrm{m}$ & 3.2808 \\
3.7854 & gal & $\mathrm{L}$ & 0.2642 \\
2.54 & inch(es) & $\mathrm{cm}$ & 0.3937 \\
25.4 & inch(es) & $\mathrm{mm}$ & 0.0394
\end{tabular}


complete. Reducing the labor required for managing these large-scale systems could prove substantial and improve the overall profitability of the farming operation.

Currently, there is no soil moisturebased irrigation system in Christmas tree production. Therefore, developing an automated system can increase the overall efficiency of irrigation systems and reduce production costs. Our system not only integrates components used earlier in other types of irrigation systems but also combines soil moisturemeasuring devices (tensiometers) with data logging and automation in an onfarm setting. The goal of this project was to design, construct, and implement a tensiometer-based automated irrigation system for fraser fir Christmas tree plantations that would (1) use existing technologies, (2) apply water based on changes in soil moisture content, (3) provide operational flexibility, and (4) interface with a computer for system changes, data collection, and system modifications. This article describes the hardware and software components of the system and discusses some of the challenges encountered in running the system.

\section{Design and concept}

Irrigation systems were constructed for experimental purposes at two Christmas tree farms in Michigan. The farms were located in Horton, MI, and Sidney, MI. At the Horton farm, the existing drip irrigation system was excavated and modified to divide the field into smaller zones allowing independent control of irrigation for each zone. At the Sidney location, a new drip irrigation system was designed and constructed for the purpose of this study.

Each system had five components: (1) a standard drip irrigation system with a 1.5-inch-diameter main line and a 1 -inch-diameter sub-main line supplying drip lines with low pressure water flow $(0.42 \mathrm{gal} / \mathrm{h})$ and 18 -inch spacing between pressure regulated emitters, (2) solenoid valves controlling the water flow to each irrigation zone, (3) soil moisture tensiometers placed in each irrigation treatment, (4) an instrument box containing data logging equipment, and (5) a relay controller able to activate the solenoids. The principle of the system was based on a simple feedback loop with the soil matric potential (SMP) (tensiometer reading) used as the control parameter and consisting of a water cycle that starts when the soil moisture tension reached a predetermined threshold. At each of the two farms, the experimental site was divided into smaller $(\approx 0.2$ acres $)$ irrigation zones for various irrigation treatments (Fig. 1). Each zone contained $7 \times 7$ rows of trees (49 trees total for each plot) and drip lines were placed along the tree rows.

For each system, a data logger (CR1000; Campbell Scientific, Logan, UT) was installed in an enclosure on a tripod (CM10, Campbell Scientific). Weather sensors including an anemometer (03101; R.M. Young, Traverse City, MI), a tipping bucket rain gauge (TE525, Campbell Scientific), a temperature/relative humidity probe (HMP50, Campbell Scientific), and a pyranometer (CS300; Apogee Instruments, Logan, UT) were installed on the tripod and wired to the data logger for continuous measurement. The data logger was programmed to scan through all sensors every minute and record at $30 \mathrm{~min}$, $\mathrm{l} \mathrm{h}$, and daily averages for all parameters determined. For simplicity, only

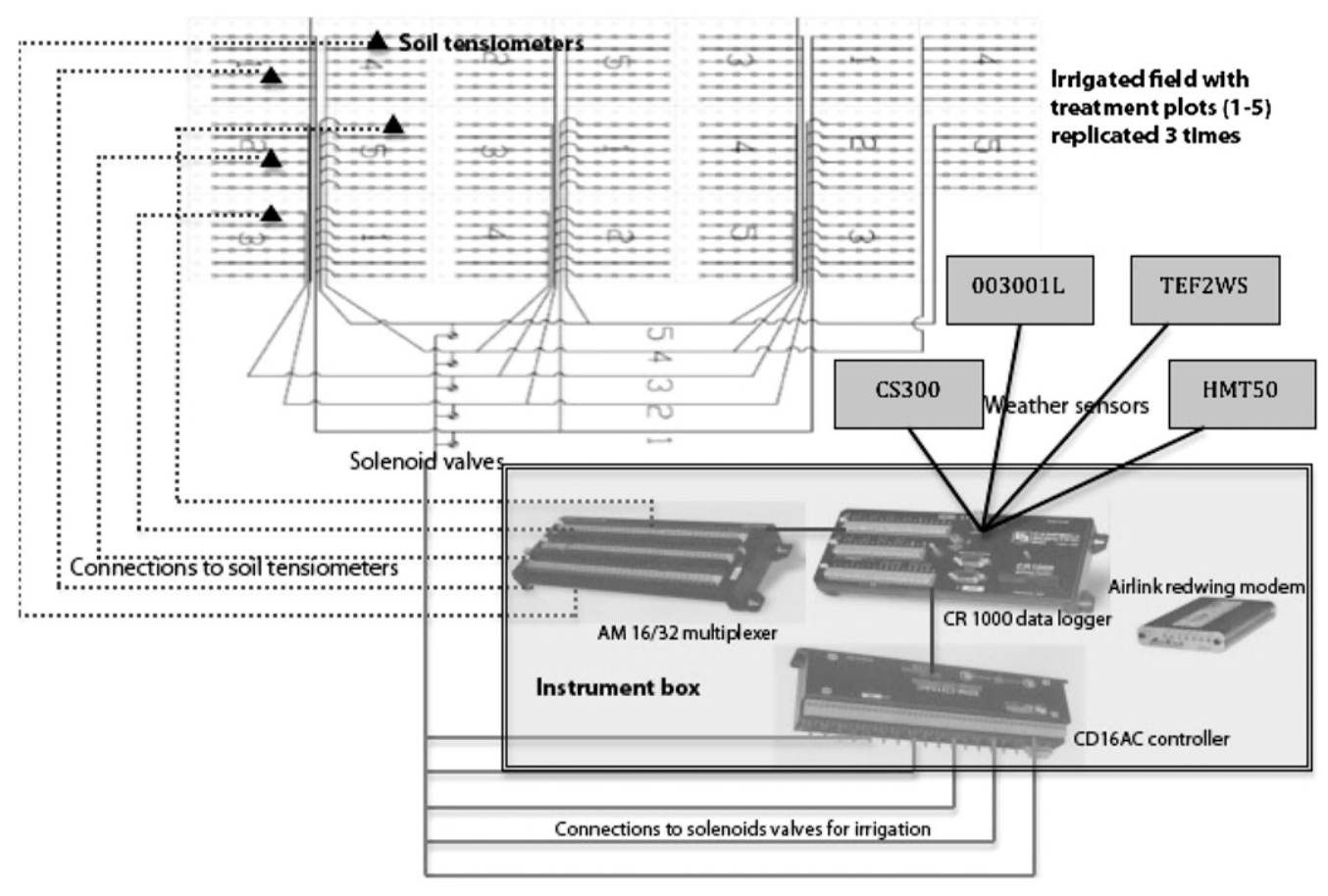

Fig. 1. Graphical design of the system indicating the wiring of the various components. The instrument box containing the data logger (CR1000; Campbell Scientific, Logan, UT), a multiplexer (AM 16/32, Campbell Scientific), a channel controller (CD16AC, Campbell Scientific), and a modem (Airlink Redwind; Sierra Wireless, Carlsbad, CA). Weather sensors installed include an anemometer (003001; R.M. Young, Traverse City, MI), a tipping bucket rain gauge (TE525, Campbell Scientific), a temperature/relative humidity probe (HMP50, Campbell Scientific), and a pyranometer (CS300; Apogee Instruments, Logan, UT). 
rainfall and tensiometer data are reported in this article.

\section{Tensiometers}

At each location, one 12 -inch tensiometer (Model SR; Irrometer, Riverside, CA) was used to monitor soil moisture and to determine irrigation timing for each treatment. The tensiometer was placed along the drip line in the center of the plot and spaced away from each drip emitter so that the distance from the tree to the emitter was about the distance from the tensiometer to the nearest emitter (Hung, 1995).

Each tensiometer was equipped with a 4- to 20-milliampere $(\mathrm{mA})$ remote-sensing units (RSUs) for connection to the data logger. The RSUs were all precalibrated and ready to use when received. As many tensiometers were connected to the system, a multiplexer (AMI6/32, Campbell Scientific) was used to increase the number of connection possibilities. The data logger reads $12-24 \mathrm{~V}$ when it scans each terminal. Consequently, it was necessary to add $100-\mathrm{ohm}$ resistors (CURS100, Campbell Scientific) to each terminal to convert the 4- to 20$\mathrm{mA}$ current into a voltage signal that the data logger could recognize during each scan. All tensiometers were hardwired to the multiplexer that was wired to the data logger (Fig. 1).

In addition, a channel controller (SDM-CDI6AC AC/DC, Campbell Scientific) was added to automate the system. The channel controller relay was wired to the data logger and connected to solenoids $(24 \mathrm{~V})$ controlling each irrigation zone or treatment (Fig. 1).

\section{Irrigation decisions}

Deciding when to irrigate, using tensiometers, is normally based on many factors including the size and physical condition of trees, soil type, and forecasted weather. Tensiometer measurements were based on matric potential ranging from field capacity $(5-10 \mathrm{kPa})$ to permanent wilting point $(>70 \mathrm{kPa})$ (Jamieson et al., 2002). The beginning and end of irrigation events in each treatment were initiated by SMP levels as measured by tensiometers installed in one replicate for each treatment. A total of four irrigation treatments $(15,25,35$, and $45 \mathrm{kPa})$ and one nonirrigated control were selected to cover a wide range of moisture conditions. However, at the Sidney location only three treatments (no irrigation, 15 , and $25 \mathrm{kPa}$ ) were used in the first year of the study, but the system was expanded during the second year to include all five treatments as described earlier.

For each treatment, the margin of acceptable change was at $\pm 2 \mathrm{kPa}$ tension range for each of the different zones, with the exception of the nonirrigated zone. If the tension exceeded the preset value for the treatment by $2 \mathrm{kPa}$, the system would activate the corresponding valve that would initiate an irrigation event for that treatment. Irrigation would stop when the tension reaches $2 \mathrm{kPa}$ below the treatment threshold. For example, for the $15-\mathrm{kPa}$ irrigation threshold, the system would start if soil moisture tension reached $17 \mathrm{kPa}$ and would stop as soon as it is below $13 \mathrm{kPa}$.

\section{Monitoring and wireless communication}

The data logger offered different options for collecting data. Either using PC400 or LoggerNet data logger support software (Campbell, Scientific), direct connection was possible using the RS-232 port and a portable computer. We preferred LoggerNet because of a better functionality for quick data examination of this software compared with PC400. However, a direct cable connection requires a computer and an operator at the location of the data logger for data download. Therefore, the option of using wireless communication was very attractive for constant remote monitoring of the data logger and the overall functioning of the system. For this purpose, a cellular modem (Raven100 CDMA; Sierra Wireless, Carlsbad, CA) was wired to the RS-232 port on the data logger. The modem has a 1-decibel (dipole), omni-directional antenna (PN 18285, Campbell Scientific) mounted on the system tripod. A data account using a dedicated internal port (IP) address for each system was setup with Alltel wireless (Little Rock, AR) for remote connection to each station from our office.

This setup allowed greater flexibility with regular monitoring of the system and data collection. In addition, customization of the software and data collection allowed incorporation of charts and graphs for a visual representation of data and alarm notifications in the event of a malfunction.
The system was operated by a computer program created using "shortcut" in the PC400 software. The program developed using a coding language called CRBasic, defined units, and provided specific instructions with all coefficients and transformations necessary to collect data that are directly usable. Furthermore, several table definitions summarizing data collected based on a predefined schedule were created and inserted into the program. The detailed computer program is available upon request addressed to the corresponding author.

\section{Tensiometer readings}

At the Horton site in 2006, there were frequent precipitation events that led to generally low readings (Fig. 2). As a consequence, there was no discernable difference between the various irrigation treatments until the time period between days 219 and 239 . This 20-d span during which there was not much rainfall had elevated SMP values, allowing a differentiation in the measurements obtained for the various irrigation treatments (Fig. 2A). Problems with the irrigation system on day 221 resulted in a failure to irrigate properly, and the $25-\mathrm{kPa}$ treatment reached a high value of $48 \mathrm{kPa}$ on day 225 before irrigation resumed, returning the $25-\mathrm{kPa}$ treatment into the desired range. From day 239, precipitation was frequent enough that all treatments were maintained near a field capacity SMP.

In 2007, precipitations were less frequent than in 2006 and there was good separation between the various treatments (Fig. 2B). Overall, the system functioned properly remaining within the $\pm 2 \mathrm{kPa}$-tolerance for each predetermined SMP treatment. Peaks in SMP measurements were immediately followed by a subsequent decrease in SMP because of an irrigation event [e.g., on days 192 and 198 for $45-\mathrm{kPa}$ treatment (Fig. 1B)]. However, there was a gap between days 177 and 184 because of system malfunction.

At the Sidney site, precipitations were also abundant and well distributed throughout most of the 2006 season, resulting in only one period where SMP reached a high level of $\approx 45 \mathrm{kPa}$ on day 251 for the control plot (Fig. $3 \mathrm{~A})$. Overall irrigation treatments ( 15 and $25 \mathrm{kPa}$ ) operated properly, maintaining the SMP within the $\pm 2 \mathrm{kPa}$ tolerance of the preset value. 



Fig. 2. Daily precipitation and soil matric potential at 12 inches $(30.5 \mathrm{~cm})$ depth for Horton, MI, in 2006 (A) and 2007 (B). Gaps in lines are due to system failures; $1 \mathrm{kPa}=1 \mathrm{cbar}, 1 \mathrm{~mm}=0.0394$ inch.

In 2007, the project site was expanded to include the four irrigation treatments and a nonirrigated treatment. There were extended periods without rainfall, allowing treatments to reach their upper limits on several occasions (Fig. 3B). Problems with the irrigation system resulted in SMP values higher than their \pm 2 -kPa threshold for the 15-kPa treatment on days 179 and 235. With the exception of these two occasions, the system operated properly and frequent wetting and drying cycles were observed (Fig. 2B).

\section{Budgeting and cost considerations}

The overall amortized cost for building an automated irrigation system in this study was $\$ 566 /$ ha per year (Table 1). This total cost included the purchase price for the piping and plumbing supplies for the drip irrigation system ( $\$ 2500 /$ ha $)$ and installation (\$100/ha) and maintenance costs (\$150/ha per year) (Ayars et al., $2007)$. The cost for adding the automation as part of the irrigation system (\$5832) was based on the assumption that two 12-inch tensiometers are used in each zone. A typical irrigated field has 20 acres and would contain five sets of tensiometers to capture soil variation across the field. The cost of the system automation includes an AM16/32 multiplexer, allowing the automation of the system to control up to 32 zones. Increasing the number of zones will add to the initial cost, but would greatly reduce the cost per zone. However, it should be noted that the system cost could be significantly reduced if only a limited number of tensiometers are used in the system and this will remove the need for a multiplexer (\$560 saving). In addition, the $100-\mathrm{ohm}$ resistor can be replaced by an inexpensive resistor from a local hardware store ( $\$ 50$ saving). The labor associated with the automated system $(\$ 1000)$ relates to the time required to setup and properly implement the system in situ. Because of the complexity of connecting and programming an automated irrigation system, there may be the possibility of a lengthy learning curve or need for technical assistance, which could increase costs. The wireless service necessary to access, modify, and view the workings of the irrigation system was based on a standard limited access data account and can vary among wireless carriers and usage. The typical cost for installing and running manual irrigation systems are $\$ 2400 /$ ha for center pivot and $\$ 1920 /$ ha to $\$ 2400 /$ ha for travelers. These do not include the cost of water supply, pump, and power unit and mainline. We anticipate that water supply and energy costs will be 

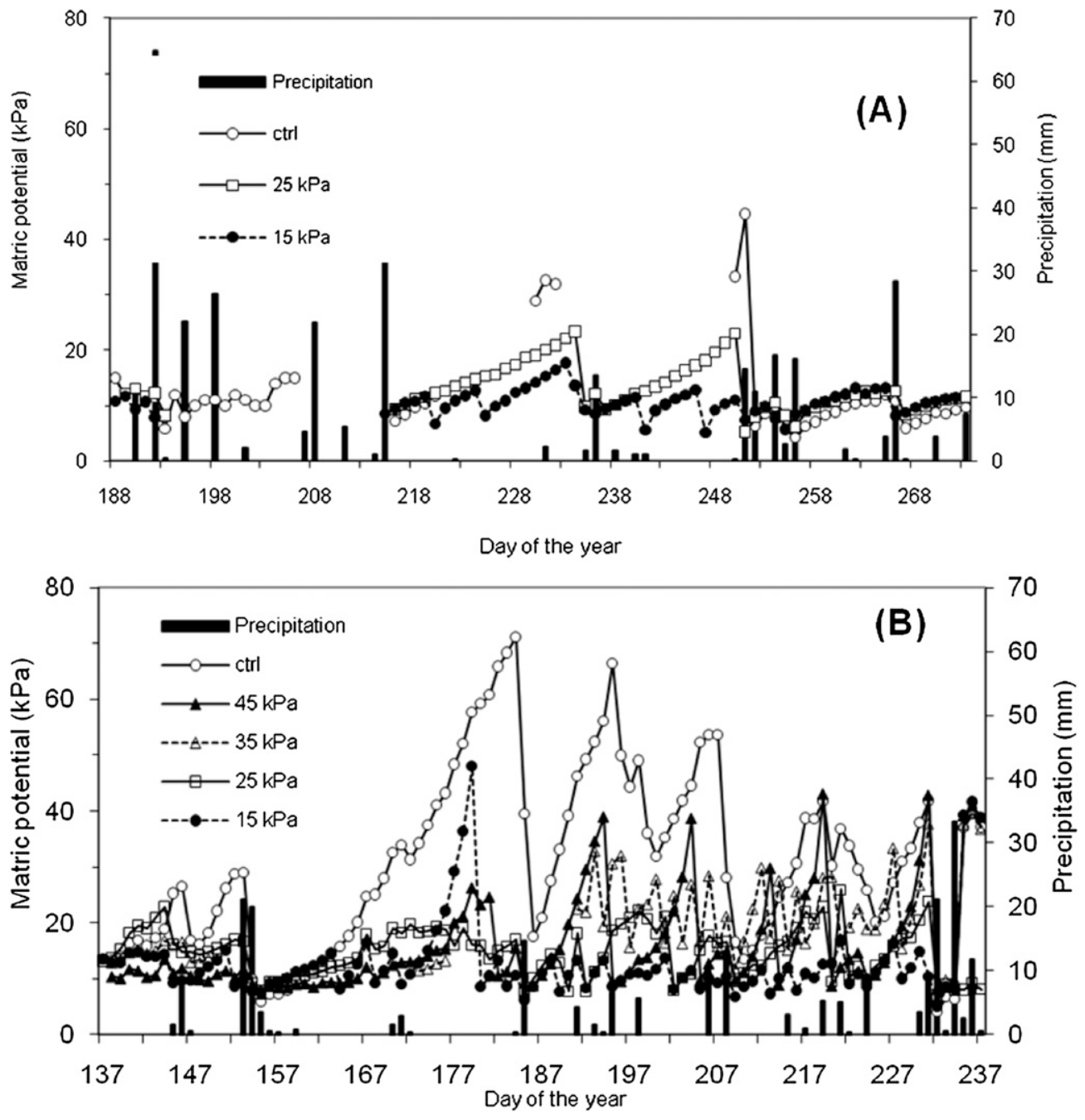

Fig. 3. Daily precipitation and soil matric potential at 12 inches $(30.5 \mathrm{~cm})$ depth for Sidney, MI, in 2006 (A) and 2007 (B). Gaps in lines are due to system failures; $1 \mathrm{kPa}=1 \mathrm{cbar}, 1 \mathrm{~mm}=0.0394$ inch.

Table 1. Total costs for components and materials associated with building an automated irrigation system.

\begin{tabular}{|c|c|c|c|}
\hline \multicolumn{2}{|l|}{ Automation/measuring system } & \multicolumn{2}{|c|}{ Irrigation system } \\
\hline Description & Costs $(\$)$ & Description & Costs $(\$)$ \\
\hline \multicolumn{4}{|c|}{ Components } \\
\hline Data logger & 1,350 & Trickle tubes & 2,000 \\
\hline Controller & 695 & Pipe (main, sub-main) & 375 \\
\hline Tensiometer (10) & 1,650 & Connections/valves & 125 \\
\hline Multiplexer & 560 & Installation & $\$ 100$ \\
\hline Resistor & 52 & & \\
\hline Wireless modem & 340 & & \\
\hline Software & 545 & & \\
\hline Labor & 1,000 & & \\
\hline Total & 6,192 & & \\
\hline Cost per hectare ${ }^{z}$ & 310 & Cost per hectare & 2,600 \\
\hline $\begin{array}{l}\text { Annual cost per hectare (10-year } \\
\text { amortization) }\end{array}$ & 31 & $\begin{array}{l}\text { Annual cost per hectare (10-year } \\
\text { amortization) }\end{array}$ & 260 \\
\hline Wireless service & 75 & & \\
\hline Annual maintenance & 50 & Annual maintenance & 150 \\
\hline Total annual cost & 156 & Total annual cost & 410 \\
\hline Annual overall cost per hectare & & & 566 \\
\hline
\end{tabular}

The data assumes 10 -year amortization on the automation equipment and pipes systems. In this example, a system is installed to irrigate a 20 -acre ( 8.09 ha) field. Data are partly based on actual expenses and from Ayars et al. (2007).

${ }^{\mathrm{z}} \$ 1.00 / \mathrm{ha}=\$ 0.4047 /$ acre. 
significantly lesser in an automated system because of increased efficiencies in water use. A study of costs and returns for producing Christmas trees indicates that it cost $\$ 276 /$ ha to $\$ 288 /$ ha per year in labor to run manual irrigation systems (Nzokou and Leefers, 2007). These basic cost information are aimed at providing an indication of the investment necessary to purchase, install, and run an automated tensiometer system. Other intangible benefits such as improved crop growth, reduced mortality, more efficient fertilization and nutrient uptake, and reduced leaching and groundwater pollution should also be valued and included in the benefits of an automated system. A cost benefit analysis is necessary to assess the full impact of such system on a farm's budget and to develop a more comprehensive comparison with other types of irrigation systems.

\section{Problems and considerations}

Although an automated irrigation system should be easier to run and more efficient than a manually controlled system, there were still a few areas of concern that should be considered. Tensiometers need to be installed and removed at the beginning and end of each growing season if freezing winter temperatures are expected. They also have to be visited regularly and refilled, especially under extended dry periods, to avoid vacuum failures. System breaks in vacuum were sometimes caused by the leaks in connection between the tip and the rest of the tensiometer. Furthermore, poor contact between the ceramic tip and the soil also led to erroneous readings, and it was necessary to change locations and reinstall the tensiometer several times during the season.

Tensiometers also have a tendency to fail in very dry soils. If an irrigation plan calls for excessive drying between irrigation events, other soil moisture measurement instruments such as TDR s should be considered. Tensiometer placement relative to emitters should be similar in relation to emitter spacing for the trees. Aside from tensiometer functionality, care should be taken in securing exposed wire connections.

Another significant problem was the need for extensive wiring, programming, and maintenance necessary to operate the system. Periodically, the system produced errors and few data points were missing or erroneous. This was more likely to occur when the frequency of data collection was increased. Using wireless data acquisition, connecting quickly and maintaining a long connection was often problematic because of intermittent cellular coverage in the area where the data logger and modem were placed. For this reason, it is advisable to control the wireless carriers that offer the strongest coverage in the area to be irrigated.

\section{Conclusions}

An automated irrigation system providing water on demand was designed and constructed at two Christmas tree farms. Elements of the system included data logging equipment, an irrigation controller, and a set of tensiometers used as trigger for the irrigation of the various zones. The system generally functioned properly with irrigation events starting immediately as soon as the soil water tension reached the predetermined threshold for each irrigation zone. However, there were several challenges associated with the extensive wiring required to setup such a system, proper design of computer programs needed to operate all sensors and controllers used for the system and maintenance of tensiometers for accurate reading of soil moisture tension. Problems encountered in this project suggest that it will be challenging to implement such a system in large-scale commercial operations without the active support of qualified irrigation technicians.

\section{Literature cited}

Al-Faraj, A., G.E. Meyer, and G.L. Horst. 2001. A crop water stress index for tall fescue (Festuca arundinacea Schreb.) irrigation decision-making: A fuzzy logic method. Comput. Electron. Agr. 32:69-82.

Ayars, J.E., D.A. Bucks, F.R. Lamm, and F.S. Nakayama. 2007. Introduction, p. 115. In: F.R. Lamm, J.E. Ayars, and F.S. Nakayama (eds.). Microirrigation for crop production. Elsevier, Oxford, UK.

Cheek, S. and R. Wilkes. 1994. Monitoring processes using wireless data acquisition. Water. Eng. Mgt. 144:22-23.

Clark, G.A., D.Z. Haman, J.F. Prochaska, and M. Yitayew. 2007. General system design principles, p. 161-219. In: F.R. Lamm, J.E. Ayars, and F.S. Nakayama (eds.). Microirrigation for crop production. Elsevier, Oxford, UK.
Erdem, T., Y. Erdem, A.H. Orta, and H. Okursoy. 2006. Use of a crop water stress index for scheduling the irrigation of sunflower (Helianthus annuus L.). Turk. J. Agr. For. 30:11-20.

Fereres, E. and D.A. Goldhamer. 2003. Suitability of stem diameter variations and water potential as indicators for irrigation scheduling of almost trees. J. Hort. Sci. Biotechnol. 78:139-144.

Hung, J.Y.T. 1995. Determination of emitter spacing and irrigation run time including plant root depth, p. 292-296. In: F.R. Lamm (ed.). Microirrigation for a changing world: Conserving resources / preserving the environment. Proc. 5th Intl. Microirrigation Congr. Orlando, FL. 2-6 Apr. 1995. Amer. Soc. Agr. Eng., St. Joseph, MI.

Irmak, S., D.Z. Haman, and H. Bastug. 2000. Determination of crop water stress index for irrigation timing and yield estimation of corn. Agron. J. 92:1221-1227.

Jones, H.G. 2004. Irrigation scheduling: Advantages and pitfalls of plant-based methods. J. Expt. Bot. 55:2427-2436.

Jamieson, T., R. Gordon, L. Cochrane, A. Madani, and G. Patterson. 2002. Tensiometers and their use in irrigation scheduling. Nova Scotia Agr. College Fact Sheet.

Klocke, N.L. and P.E. Fischbach. 1984. Estimating soil moisture by appearance and feel. Univ. of Nebraska Coop. Ext. Rpt. G84-690-A.

Koelling, M.R., J.B. Hart, and L.A. Leefers. 1992. Status and potential of Michigan agricultural phase II: Christmas tree production. Michigan Agr. Expt. Sta. Spec. Rpt. No. 61.

Muñoz-Carpena, R., M.D. Dukes, Y.C. $\mathrm{Li}$, and W. Klassen. 2005. Field comparison of tensiometer and granular matrix sensor automatic drip irrigation on tomato. HortTechnology 15:584-590.

Nzokou, P., N.J. Gooch, P. Nikiema, and B.M. Cregg. 2007. The "one-inch rainfall per week" rule for irrigation of fraser fir: Assessing the rule using data collected at two tree farms in Michigan. Great Lakes Christmas Tree J. 2:16-28.

Nzokou, P. and L.A. Leefers. 2007. Costs and returns in Michigan Christmas tree production. Mich State Univ. Ext. Bul. 2999.

Oki, L.R., J.H. Lieth, and S. Tjosvold. 1996. Tensiometer-based irrigation of cut-flower roses: Report to the California Cut-Flower Commission. Univ. of California, Davis.

Orta, A.H., Y. Erdem, and T. Erdem. 2003. Crop water stress index for watermelon. Sci. Hort. 98:121-130. 


\section{Technology and Product Reports}

Payero, J.O., C.M.U. Neale, and J.L. Wright. 2005. Non-water stress baselines for calculating crop water stress index (CWSI) for alfalfa and tall fescue grass. Trans. Amer. Soc. Agr. Eng. 48:653661.

Smajstrla, A.G. and S.J. Locascio. 1996. Tensiometer-controlled, drip-irrigation scheduling of tomato. Appl. Eng. Agr. 12:315-319.
Shukla, S., C.Y. Yu, J.D. Hardin, and F.H. Jaber. 2006. Wireless data acquisition and control systems for agricultural water management projects. HortTechnology 16:595-604.

VanderGulik, T. 2006. Water conservation fact sheet: Irrigation scheduling techniques. Brit. Columbia Ministry of Agr. and Food Rpt. 577.100-1.
Yazar, A., T.A. Howell, D.A. Dusek, and K.S. Copeland. 1999. Evaluation of crop water stress index for LEPA irrigated corn. Irr. Sci. 18:171-180.

Young, M.H. and J.Y. Sisson. 2002. Tensiometry, p. 575-609. In: J. Dane and C. Topp (eds.). Methods of soil analysis, Part 4. Soil Sci. Soc. Amer. Book Ser. 5. Amer. Soc. Agron., Madison, WI. 